\title{
Effectiveness of intraoperative indocyanine green videoangiography in direct surgical treatment of pediatric intracranial pial arteriovenous fistula
}

\author{
Tadashi Sugimoto, MD, ${ }^{1}$ Young-Su Park, MD, ${ }^{2}$ Ichiro Nakagawa, MD, ${ }^{2}$ Fumihiko Nishimura, MD, ${ }^{2}$ \\ Yasushi Motoyama, MD, ${ }^{2}$ and Hiroyuki Nakase, MD${ }^{2}$
} 1Department of Neurosurgery, Higashiosaka City General Hospital, Osaka; and ²Department of Neurosurgery, Nara Medical
University, Nara, Japan

\begin{abstract}
Intracranial pial arteriovenous fistulas (AVFs) are rare cerebrovascular lesions. The authors report a rare case of pediatric pial AVF treated by direct disconnection with the aid of indocyanine green (ICG) videoangiography. A 3-year-old girl presented with developmental problems. Magnetic resonance imaging revealed brain atrophy and an anomalous left temporal vascular mass. Angiography showed a high-flow pial AVF in the early arterial phase fed by the $M_{1}$ portion of the left middle cerebral artery and draining into the superficial sylvian vein and the vein of Trolard with a large varix. Given that her fistula was located in a superficial region that was easily accessible by craniotomy, the authors successfully disconnected her pial AVF by direct surgery aided by ICG videoangiography, which clearly confirmed the shunting point. In this report, the authors discuss the existing literature and compare the relative merits of endovascular versus surgical options for the treatment of pial AVF.
\end{abstract}

http://thejns.org/doi/abs/10.3171/2014.9.PEDS13683

KEY WORDS pial arteriovenous fistula; indocyanine green videoangiography; direct surgery; varix; pediatric; embolization; vascular disorders

$\mathrm{I}$ NTRACRANIAL pial arteriovenous fistulas (AVFs) are rare vascular lesions of the brain and account for $1.6 \%-4.7 \%$ of all intracranial arteriovenous malformations (AVMs). ${ }^{3,17,19}$ These lesions differ from AVMs in that they involve direct connections between an artery and vein, have no nidus, and are composed of one or more direct arterial feeding vessels with a single draining vein. They also differ from dural AVFs in that they derive their arterial supply from pial or cortical arterial vessels and because the lesions do not lie within the intradural region.

Because of their high-flow nature, they are often associated with a venous varix. ${ }^{4}$ Because pial AVFs carry a high risk of intracranial hemorrhage, the clinical diagnosis of pial AVF, followed by prompt and appropriate treatment, is important. ${ }^{10}$ To date, fewer than 150 cases of pial AVFs have been reported, and the natural history and developmental mechanisms of these lesions remain unclear. ${ }^{3,8,18}$
The goal of treatment is to obliterate the arteriovenous shunt, with preservation of the normal arterial supply and venous drainage of the normal brain tissue. However, the identification of the fistula point is occasionally obscured on digital subtraction angiography. Microscopy-integrated indocyanine green (ICG) videoangiography has recently become widespread as an effective method for the surgical treatment of conditions such as AVMs and aneurysms. Many reports in which ICG was used for treatment of an AVM or aneurysm have been published..$^{15}$ To date, however, there have been no reports of ICG used for the treatment of a pial AVF with direct surgical intervention.

We report the efficacy of ICG videoangiography in the case of a pediatric patient with pial AVF who had a giant venous varix on the left temporal lobe. This technique allowed us to successfully treat this patient by surgically disconnecting the fistulas.

ABBREVIATIONS AVF = arteriovenous fistula; $A \mathrm{VM}=$ arteriovenous malformation; $\mathrm{DQ}=$ developmental quotient; ICG = indocyanine green; ICP = intracranial pressure;

$\mathrm{MCA}=$ middle cerebral artery.

SUBMITTED December 19, 2013. ACCEPTED September 15, 2014

INCLUDE WHEN CITING Published online October 24, 2014; DOI: 10.3171/2014.9.PEDS13683.

DISCLOSURE The authors report no conflict of interest concerning the materials or methods used in this study or the findings specified in this paper. 


\section{Case Report}

History and Examination

A 6-month-old infant girl with a slight head injury was admitted to our hospital. Results of her general and neurological examinations were normal, but she had macrocephaly with a head circumference of $48 \mathrm{~cm}$. Computed tomography showed brain atrophy and a left temporal vascular anomalous mass that was unrelated to her head injury. We recommended a detailed examination of the macrocephaly and vascular anomaly, but her parents rejected our suggestion because she showed no focal signs or other complications such as heart failure, and her family had other financial constraints because of her brother's illness and mother's pregnancy. From these results, we initially decided to follow up on the girl as an outpatient. We expected that the vascular malformation would gradually cause her to exhibit developmental problems. At 3 years of age, her overall developmental quotient (DQ) as assessed by the Kyoto Scale of Psychological Development 2001 was 75 (Postural-Motor DQ 85, Cognitive-Adaptive DQ 76, and Language-Social DQ 73); therefore, we decided to conduct a detailed examination of the vascular anomaly and treat it at that time.

\section{Operation}

Treatment was initiated when the patient was 3 years old. Magnetic resonance imaging revealed a flow void of vascular mass in the left temporal subdural region and a high degree of brain atrophy for her age (Fig. 1). Angiography showed a high-flow pial AVF in the early arterial phase fed by the $\mathrm{M}_{1}$ portion of the left middle cerebral artery (MCA) and draining into the superficial sylvian vein and the vein of Trolard (Fig. 2). We were able to identify dilation of the left superior orbital vein and subcutaneous vein in the forehead because of venous hypertension. We could not detect the nidus but could confirm a large varix. The 3D CT scan showed 2 fistulous points and the large varix just behind them (Fig. 3). Surgical disconnection of the fistula was chosen as the preferred method of treatment, rather than an endovascular coil embolization, because the superior temporal artery had increased tortuosity and the location of the lesion was easily accessible.

Direct surgical treatment via left frontotemporal craniotomy was performed under general anesthesia. After we opened the dura mater, a thickened white arachnoid was visible and we were able to identify the red sylvian vein. We dissected this arachnoid membrane and exposed the left MCA from the $\mathrm{M}_{1}$ distal portion to the $\mathrm{M}_{3}$ portions. As seen on 3D CT scans before surgery, we recognized 2 fistulous points between the $\mathrm{M}_{2}$ portion of the MCA and a large varix. At this point $1.5 \mathrm{mg}$ of ICG was intravenously injected, and approximately 15 seconds after ICG injection we could clearly identify that the injected dye ran up to the venous varix through the 2 fistulous shunting points. Consequently, we directly clipped the 2 fistulous points. After obliteration of the fistulas, ICG was reinjected with subsequent demonstration of normal flow (Fig. 4). Last, we ligated the large varix to completely disconnect the arterial-venous shunt. Soon after clipping, the superficial sylvian veins returned to their normal venous color.
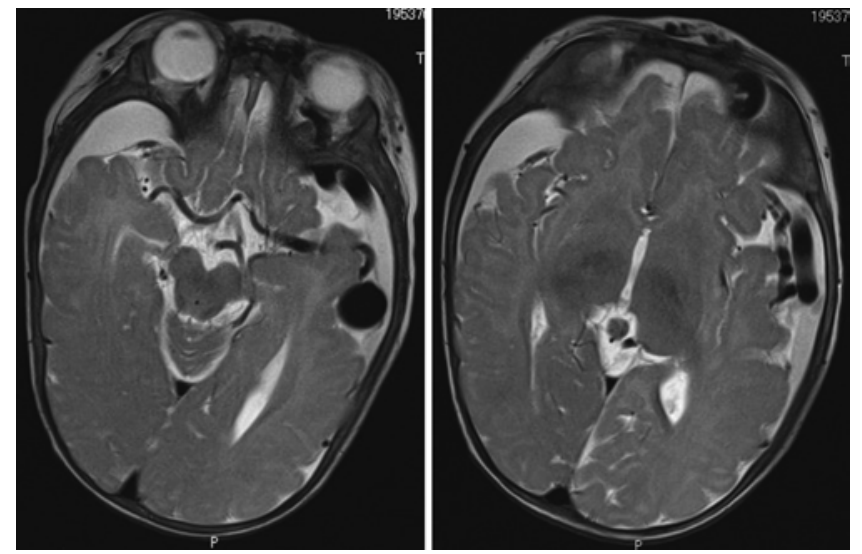

FIG. 1. Axial T2-weighted MR images showing the flow void of vascular mass in the left temporal subdural region and associated brain atrophy.

\section{Postoperative Course}

After the operation, the patient was kept under sedation with barbiturate therapy for 3 days to prevent postoperative hyperperfusion syndrome. She experienced no postoperative neurological deterioration or hyperperfusion syndrome and was discharged from our hospital with ambulatory status 2 weeks after the operation. Obliteration of the pial AVF was reconfirmed by postoperative 3D CT angiography 6 months after the surgery (Fig. 5). Recovery from her developmental delay was shown by her DQ scores for the Kyoto Scale of Psychological Development 2001, 1 year after the surgery. Her overall DQ was 96 (Postural-Motor DQ 103, Cognitive-Adaptive DQ 95, and Language-Social DQ 94).

\section{Discussion}

Intracranial pial AVFs have only recently been considered as distinct from AVMs. ${ }^{7}$ The prevalence of intracranial pial AVF is unknown. In a series of 320 AVMs reported by Halbach et al., pial single-channel AVFs accounted for only $1.6 \%$ of all lesions. ${ }^{3}$ Weon et al. reported a $4.2 \%$ prevalence of pial AVFs in their patient series (52 of 1248), ${ }^{19}$ whereas Tomlison et al. reported a prevalence of $4.7 \% .{ }^{17}$ Intracranial pial AVFs are often associated with cerebral AVMs or are sometimes observed as multiple AVFs. ${ }^{7}$ They are usually diagnosed during infancy or early childhood and are considered congenital in the vast majority of cases. They form a part of syndromes such as Rendu-Osler-Weber or Klippel-Trenaunay-Weber syndrome, consistent with the fact that a genetic abnormality contributes to their etiology., 5,13,18 Acquired pial AVFs are very rare and are the result of traumatic injury or iatrogenic causes. Our patient had a minor head injury, but it was difficult to identify whether this head injury was the cause of the pial AVF from her initial CT scan. From the initial $\mathrm{CT}$, we assumed that her pial AVF was not a secondary lesion, but was congenital in nature.

The pathophysiological mechanisms of pial AVFs remain unclear. Lasjaunias proposed that structural congenital alterations are primarily responsible for vascular remodeling processes, affecting the endothelial cells at the venous side of the capillaries. Furthermore, these al- 

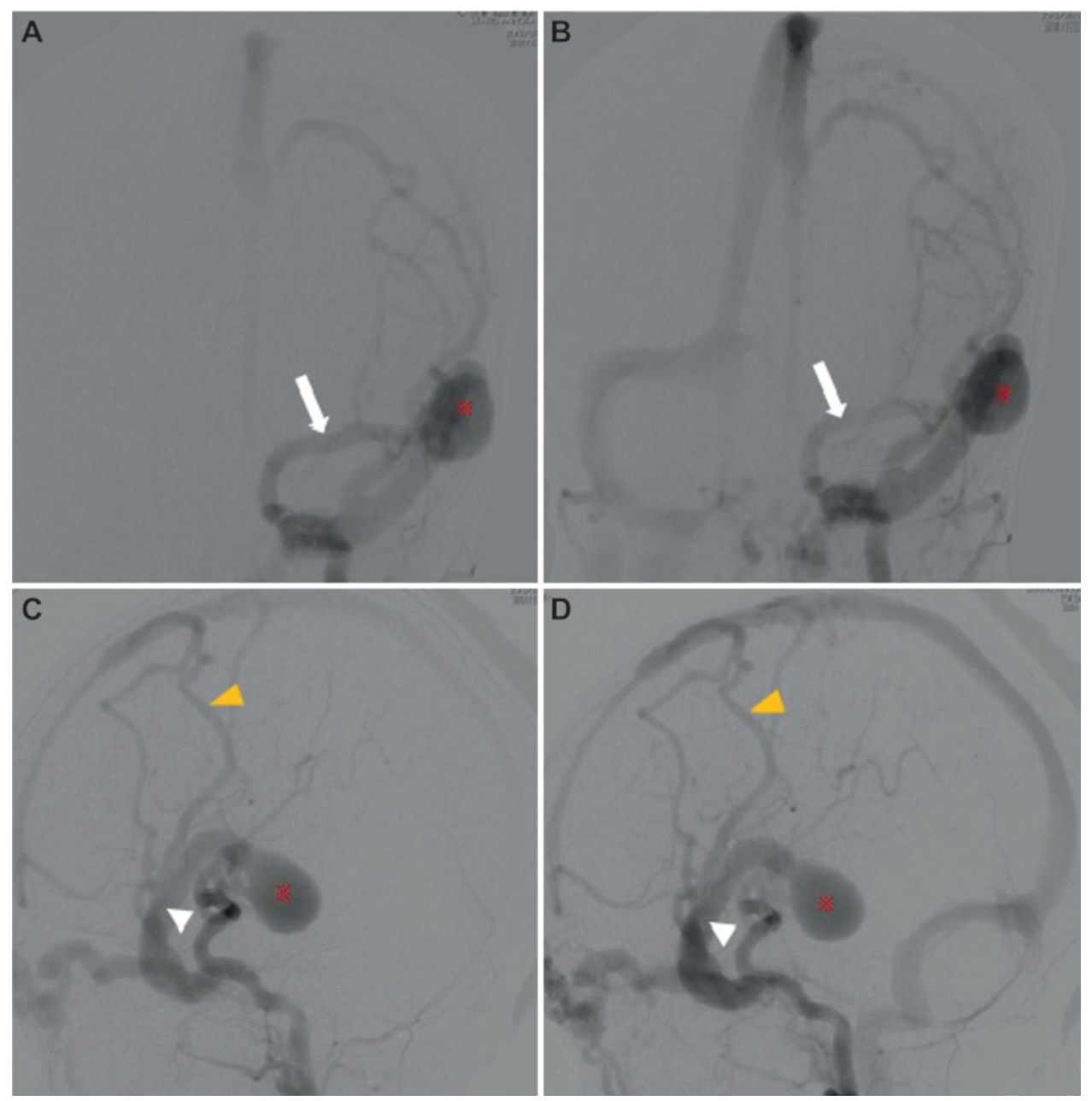

FIG. 2. Left internal carotid angiograms. Anteroposterior ( $A$ and $B$ ) and lateral ( $C$ and $D)$ views showing the high-flow pial $A V F$ in the early arterial phase fed by the $\mathrm{M}_{1}$ portion of the left MCA and draining into the superficial sylvian vein and the vein of Trolard. (Arrows: MCA; white arrowheads: superficial sylvian vein; yellow arrowheads: vein of Trolard; and $*$ : varix.) Figure is available in color online only.

terations would remain in a quiescent dysfunctional state, such that their structural manifestation would only occur in response to triggers that might include mechanical, hormonal, hemodynamic, pharmacological, thermal, radiological, infective, or metabolic factors. ${ }^{6}$

The natural history of pial AVFs is unknown. They can cause seizures, hemorrhage, headache, neurological deficits, and symptoms of increased intracranial pressure (ICP)., ${ }^{1,2}$ In infants, pial AVFs may cause heart failure and macrocephaly because of their high-flow nature and increased ICP. At 6 months of age, our patient did not experience heart failure, but she had a giant varix and was macrocephalic. Nelson et al. previously reported that 5 of 8 patients with conservatively treated pial AVFs died. ${ }^{12}$ Spontaneous closure of pial AVFs has been reported only in 1 case. ${ }^{16}$ The high-flow shunt in pial AVFs causes high ICP because of venous congestion; as a result, patients with these lesions often have huge venous varices that can lead to intracranial hemorrhage. Because of low perfusion in the normal brain tissue and intracranial venous congestion, these lesions may also affect normal brain development and cause cognitive impairment, especially in infants. Our patient had multihole arteriovenous shunts, a huge varix, and brain atrophy in the ipsilateral hemisphere on CT and MRI studies. Given these symptoms, we planned to treat the pial AVF as soon as it was reasonable to prevent future intracranial hemorrhage and developmental delay.

The predominant treatment options for these lesions are either direct surgical disconnection, endovascular embolization, or a combination of surgical and endovascular procedures. Over the past 2 decades, improvements in microcatheters and guidewires, and increased experience on the part of practitioners, have led to the evolution of endovascular techniques. ${ }^{8,11}$ The less invasive nature of these procedures has made endovascular treatment the preferred modality for patients with pial AVF, with surgical treatment reserved for a few selected cases in which it was deemed necessary. ${ }^{14}$ However, a review by Yang et al. of the literature from 1977 to 2009 revealed an obliteration rate of $86.5 \%$ (32 patients) for endovascular treatment, but a comparatively higher obliteration rate $(96.8 \%$ in 30 patients) for surgical treatment. ${ }^{20}$ Weon et al. reported that in 34 of 35 pial AVFs treated by endovascular methods, 2 to 3 sessions were required in nearly half of the cases, and 


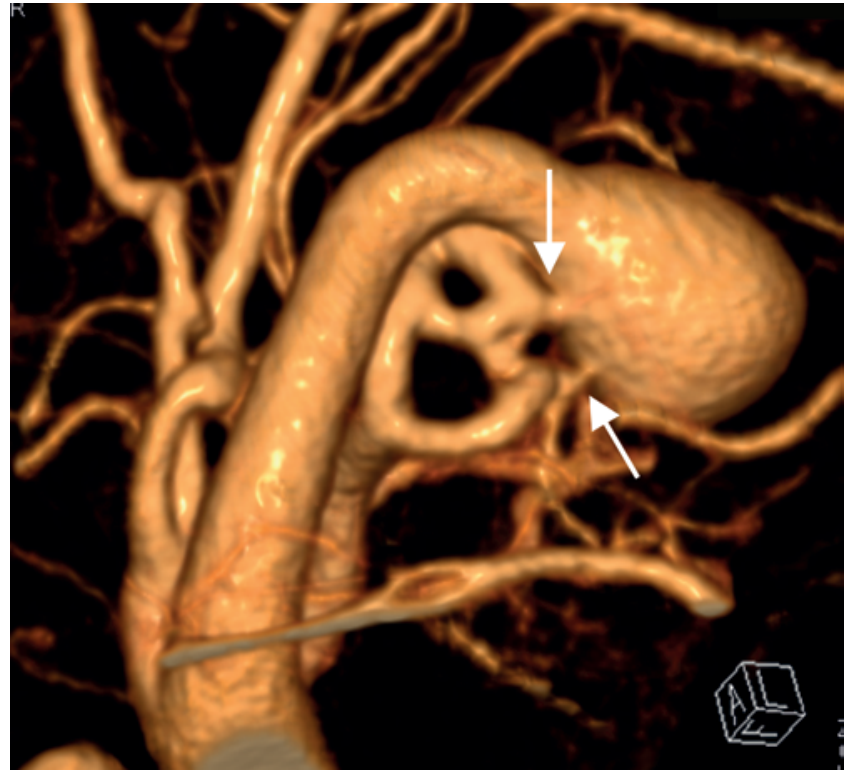

FIG. 3. Preoperative 3D CT scan showing 2 fistulous points (arrows) and a large varix just behind them. Figure is available in color online only.

in $17 \%$ of the cases, 4 to 5 sessions were necessary. They pointed out that the arterial feeding vessels are often tiny and difficult to access, and the cumulative risk of multiple, staged embolization procedures may exceed the risk of craniotomy for superficial lesions. They also argued that, especially in young patients, repeated exposure to radiation should be avoided. ${ }^{19}$

In our patient, we performed direct surgical disconnection with the aid of intraoperative ICG videoangiography via frontotemporal craniotomy because the lesion was easily accessible and because we aimed for complete disconnection of the fistulas in a single procedure. Fluorescence angiography has recently become popular as a viable option because it allows direct visualization of the lesion. ${ }^{9}$ The efficacy of ICG videoangiography during aneurysmal surgeries, extracranial-intracranial bypass, and AVM surgeries has been reported..$^{15}$ This technique offers real-time information on vessel flow, even in tiny perforators, which are difficult to identify with digital subtraction angiography.

In our case, intraoperative ICG videoangiography clearly demonstrated the precise location of the 2 fistula points, and enabled us to totally disconnect the fistulas; moreover, repeated postoperative ICG videoangiography confirmed complete disconnection of the fistulas. This is the first report showing intraoperative ICG videoangiography to be a very effective option for the direct surgical treatment of pial AVFs.

Although endovascular treatments are increasingly being adopted as very effective methods of treating pial
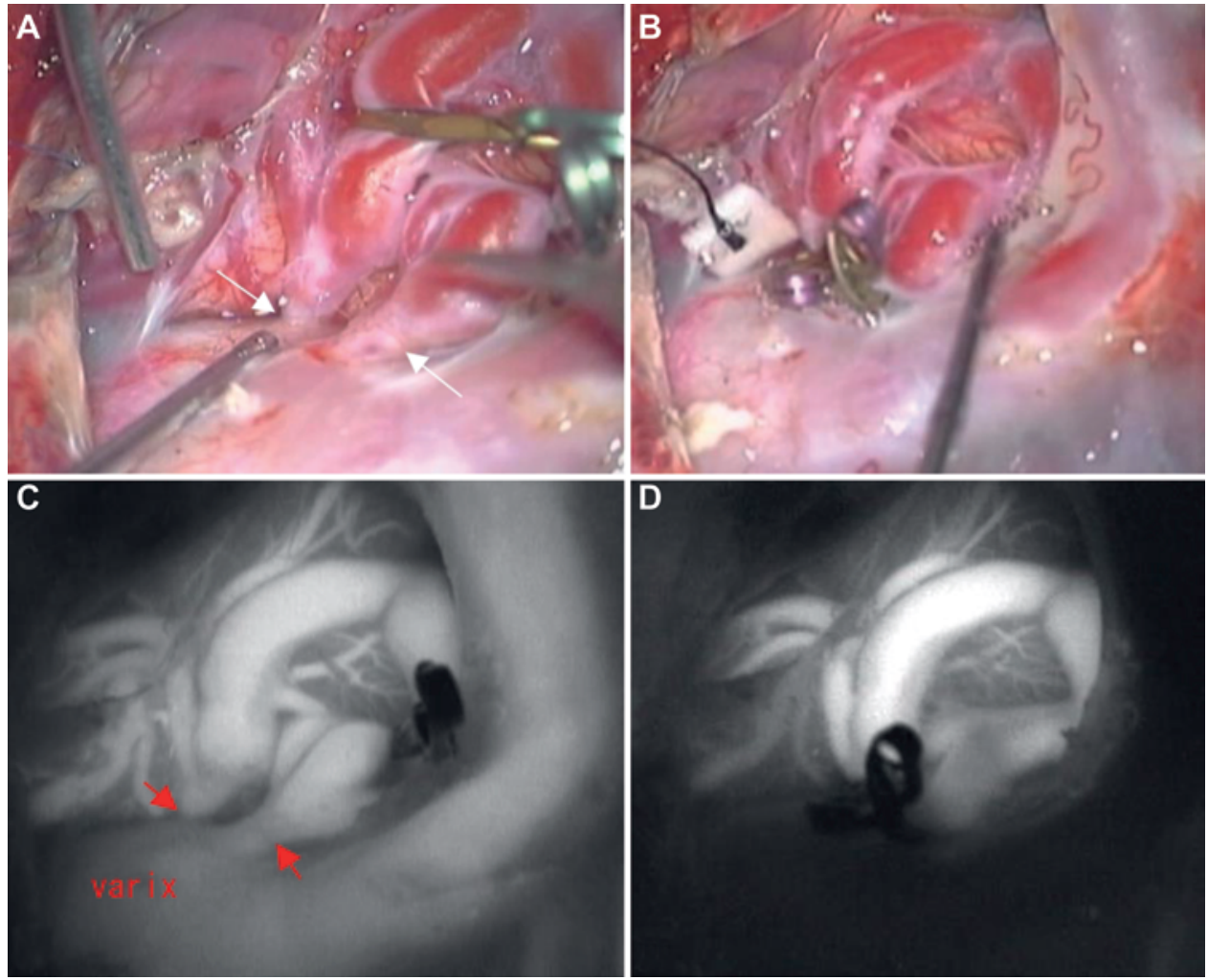

FIG. 4. Intraoperative photographs obtained before (A) and after (B) obliteration of the fistula (A: white arrows) with 2 clips. An ICG videoangiography study (C) clearly demonstrating 2 fistulous points (red arrows) and a large varix between the fistula and draining vein. An ICG videoangiography study (D) obtained after obliteration of the fistula demonstrating normal arterial flow and the disappearing abnormal shunt. Before obliteration, we used the temporary clip at the main feeding arteries to reduce flow pressure against the varix. Two main feeding vessels were temporarily clipped $(A)$, and one feeder was temporarily clipped $(C)$ before obliteration of the fistula. Figure is available in color online only. 


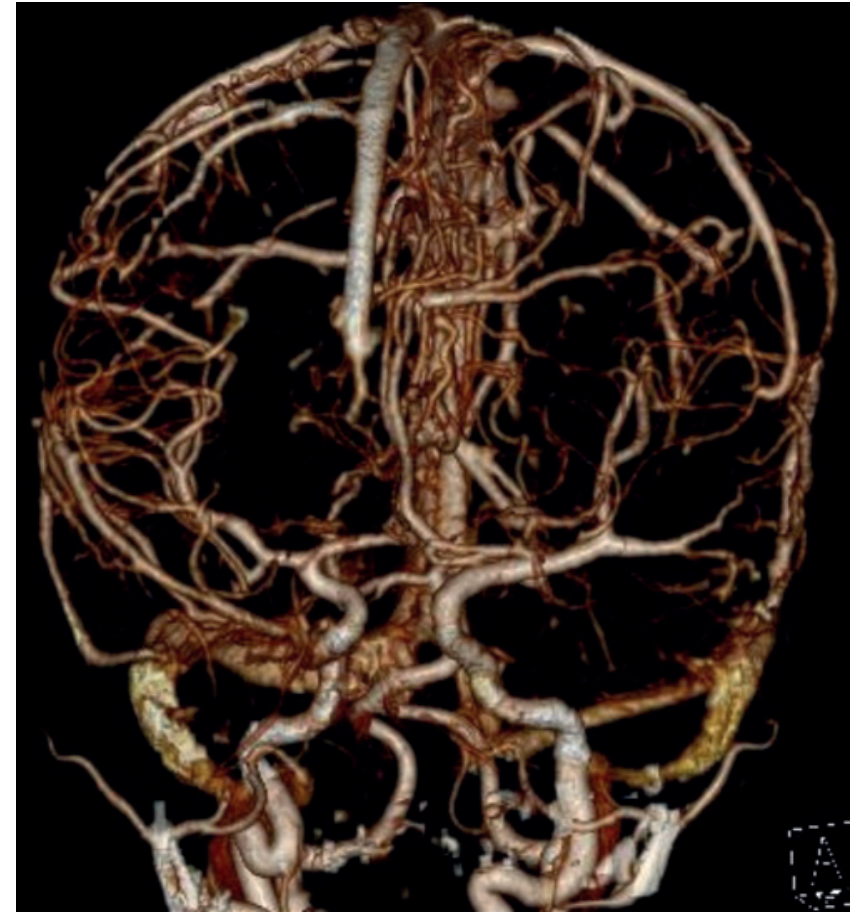

FIG. 5. Postoperative 3D CT angiography study obtained 6 months after operation showing complete obliteration of the fistula and a normal left MCA. Figure is available in color online only.

AVFs, we recommend direct disconnection of these lesions via intraoperative ICG videoangiography if fistulas are located in superficial regions and are easily accessible via craniotomy.

\section{References}

1. Aoki N, Sakai T, Oikawa A: Intracranial arteriovenous fistula manifesting as progressive neurological deterioration in an infant: case report. Neurosurgery 28:619-623, 1991

2. García-Mónaco R, Taylor W, Rodesch G, Alvarez H, Burrows $\mathrm{P}$, Coubes $\mathrm{P}$, et al: Pial arteriovenous fistula in children as presenting manifestation of Rendu-Osler-Weber disease. Neuroradiology 37:60-64, 1995

3. Halbach VV, Higashida RT, Hieshima GB, Hardin CW, Dowd CF, Barnwell SL: Transarterial occlusion of solitary intracerebral arteriovenous fistulas. AJNR Am J Neuroradiol 10:747-752, 1989

4. Hoh BL, Putman CM, Budzik RF, Ogilvy CS: Surgical and endovascular flow disconnection of intracranial pial singlechannel arteriovenous fistulae. Neurosurgery 49:1351-1364, 2001

5. Kikuchi K, Kowada M, Sasajima H: Vascular malformations of the brain in hereditary hemorrhagic telangiectasia (Rendu-Osler-Weber disease). Surg Neurol 41:374-380, 1994

6. Lasjaunias P: A revised concept of the congenital nature of cerebral arteriovenous malformations. Interv Neuroradiol 3:275-281, 1997

7. Lasjaunias P, Manelfe C, Chiu M: Angiographic architecture of intracranial vascular malformations and fistulas-pretherapeutic aspects. Neurosurg Rev 9:253-263, 1986

8. Madsen PJ, Lang SS, Pisapia JM, Storm PB, Hurst RW, Heuer GG: An institutional series and literature review of pial arteriovenous fistulas in the pediatric population. Clinical article. J Neurosurg Pediatr 12:344-350, 2013
9. Miyoshi Y, Yasuhara T, Nishida A, Tokunaga K, Sugiu K, Date I: Effectiveness of intraoperative near-infrared indocyanine green videoangiography in a case with recurrent spinal perimedullary arteriovenous fistula. Clin Neurol Neurosurg 113:239-242, 2011

10. Morimoto T, Yamada T, Hashimoto H, Tokunaga H, Tsunoda S, Sakaki T: Direct approach to intracranial vertebral arteriovenous fistula. Case report. Acta Neurochir (Wien) 137:98-101, 1995

11. Nakiri GS, Abud TG, Oliveira RS, Santos AC, Machado HR, Abud DG: Endovascular treatment of intracranial pial arteriovenous fistula. Arq Neuropsiquiatr 68:463-465, 2010

12. Nelson K, Nimi Y, Lasjaunias P, Berenstein A: Endovascular embolization of congenital intracranial pial arteriovenous fistulas. Neuroimaging Clin N Am 2:309-317, 1992

13. Oyesiku NM, Gahm NH, Goldman RL: Cerebral arteriovenous fistula in the Klippel-Trenaunay-Weber syndrome. Dev Med Child Neurol 30:245-248, 1988

14. Paramasivam S, Toma N, Niimi Y, Berenstein A: Development, clinical presentation and endovascular management of congenital intracranial pial arteriovenous fistulas. J Neurointerv Surg 5:184-190, 2013

15. Raabe A, Beck J, Gerlach R, Zimmermann M, Seifert V: Near-infrared indocyanine green video angiography: a new method for intraoperative assessment of vascular flow. Neurosurgery 52:132-139, 2003

16. Santosh C, Teasdale E, Molyneux A: Spontaneous closure of an intracranial middle cerebral arteriovenous fistula. Neuroradiology 33:65-66, 1991

17. Tomlinson FH, Rüfenacht DA, Sundt TM Jr, Nichols DA, Fode NC: Arteriovenous fistulas of the brain and the spinal cord. J Neurosurg 79:16-27, 1993

18. Wang YC, Wong HF, Yeh YS: Intracranial pial arteriovenous fistulas with single-vein drainage. Report of three cases and review of the literature. J Neurosurg (2 Suppl Pediatrics) 100:201-205, 2004

19. Weon YC, Yoshida Y, Sachet M, Mahadevan J, Alvarez H, Rodesch G, et al: Supratentorial cerebral arteriovenous fistulas (AVFs) in children: review of 41 cases with 63 non choroidal single-hole AVFs. Acta Neurochir (Wien) 147:17-31, 2005

20. Yang WH, Lu MS, Cheng YK, Wang TC: Pial arteriovenous fistula: a review of literature. Br J Neurosurg 25:580-585, 2011

\section{Author Contributions}

Conception and design: Sugimoto, Park, Nakagawa. Analysis and interpretation of data: all authors. Drafting the article: Sugimoto. Critically revising the article: Sugimoto. Reviewed submitted version of manuscript: all authors. Study supervision: Sugimoto.

\section{Supplemental Information}

\section{Ethics Approval}

This study was approved by the Nara Medical University Ethics Committee. Written informed consent was obtained for publishing of this case report and accompanying images. A copy of the written consent is available for review on request.

\section{Correspondence}

Tadashi Sugimoto, Department of Neurosurgery, Higashiosaka City General Hospital, 3-4-5 Nishiiwata, Higashiosaka, Osaka 578-8588, Japan. email: sugimoto-t@ @igashiosaka-hosp.jp. 